\title{
Audit and Analysis Methodology for the Effectiveness of Investment Decisions: The Development Model of Reference Solutions
}

\author{
Rodnyansky D.V. ${ }^{1,{ }^{*}}$ Makarov I.V., ${ }^{2,}$ Bykau A.A. ${ }^{3,}$ Shamrina I.V. ${ }^{2}$ \\ ${ }^{1}$ Kazan Federal university, Kazan, 420008, Russia \\ ${ }^{2}$ Financial university under the Government of the Russian Federation, Lipetsk, Russia \\ ${ }^{3}$ Belarus State economic university, Minsk, Republic of Belarus \\ *Corresponding author. Email: drodnyansky@gmail.com
}

\begin{abstract}
This work is devoted to the development of a formation methodology of "reference" solutions that can be used as a model to compare when conducting a performance audit within the program-target management mechanism. The main attention in the work is focused on the development of a model that allows, with a high degree of objectivity, determining close to optimal parameters of a managerial decision based on the data of accounting and statistical systems regarding the targeted use of public funds, which are necessary for the process of implementing performance audit tools as a basis for comparative analysis. The aim of the work is to develop the theoretical and methodological principles of "reference" solutions formation, which should be used as a comparison basis when conducting the performance audit procedures. The methods of scientific analysis were used while researching. They are dialectical, comparative-economic and statistical, systematic, systemic-functional and historical genetic analysis, mathematical economic modeling, management theory of organizational and economic systems and the method of scientific abstraction. Their complex use allowed to provide the authenticity of the conducted research.
\end{abstract}

Keywords: performance audit, model, reference model, management, information

\section{INTRODUCTION}

A successful functioning of every management subsystem in the social-economic system needs qualitative information assurance.

However, it needs to set the effective feedback, too.

Moreover, the information support system for the development and implementation of management decisions in the mechanism of program-targeted management is made on the principle of induction accumulation of information, involving the collecting and generalizing of information supplied by accounting systems of individual business entities (micro-level), its processing and analyzing at the regional level in order to develop programs of regional and sectorial development (meso-level) and, finally, the processing of already statistical information supplied by regional statistical agencies, for indicative and/or policy-planning development of the regions, economic branches, businesses and the entire socio-economic system.

The given information supply is needed to develop and fulfill the programs of the social-economic development of a region. $[1,2,3]$.

However, it is only one side of the issue.

\begin{abstract}
The second component of the information support system for the acceptance and implementation of management decisions should be an effective feedback loop. [4,5]

However, if the accounting system of enterprises and the system of state statistical accounting should be the basis for the primary information collection, then for the implementation of the feedback loop and the conduction of control functions, as international experience shows, the performance audit tools are the most effective.

At the same time, the use of this toolkit has its complications. [6,7]

First of all, for the implementation of the performance audit, some criteria of effectiveness must present. They are such "models" which the being-made management decisions can be compared to. [8]

It can be exemplified with the provided toolkit for acceptance of effective decisions for funding the industry development program, which also can be used as the performance audit toolkit. $[9,10]$
\end{abstract}




\section{METHODOLOGY}

As an object-base for the formation of a decision-making system and following control of their effectiveness, the agricultural sector of the region can be taken.

To form the effective system of the agricultural industry as the strategic field, solving a number of tasks, including the following, is needed:

1. The development of production and transport infrastructure, including in rural areas;

2. The enough financial provision to buy a breeding flock, seed bank, agricultural appliance, spare parts, fuel and lubrication materials;

3. The enough ecological production provision in order to eliminate the risks of removing the lands, which the agricultural activity is on, from agricultural and/or other turns.

4. The development of industrial manufactories, specialized in the production of modern high-effective equipment for agricultural activity.

As can be seen, from the given key tasks only one is in direct relationships with agriculture. The others are connected with the economy-wide problematics. This connection is explained by the strategic character of the agricultural production sphere, its mutual interaction and connection with other types of production, first of all, industry and national infrastructure.

Accordingly, when developing and implementing the state policy for the development of agricultural production, it is necessary to develop a common vector (a target set) of state policy, including as subgoals the development of related, and significantly affecting on the development of agricultural production, industrial productions.

In this article, a formal model for the formation and optimal implementation of the state policy for the development of agricultural production and related industries and infrastructure based on targeted budget and mixed funding, which can be used as the basis for the performance audit toolkit, is developed.

As a basic assumption for the formation of the model, the thesis is put forward that state policy, in accordance with the practice adopted in our country, will be implemented in the form of a state target program, which will be arbitrarily called the "program for ensuring the sustainable development of agricultural and related industrial production".

It can be assumed that the implementation of the program for the agriculture development, and related industrial production and infrastructure is carried out for account of the State budget and related funds.

As the main goals of this program, it is necessary to position those goals that will contribute to achieving food security in the current and strategic perspective.

Based on the goals of state funding of this program, together with the constituent subprograms, the basis for constructing the indicator of the $\mathrm{i}$-th goal should be a longterm stable increase in the efficiency of agricultural and related industrial production, expressed in a quantitative increase in the production of high-quality agricultural or industrial products. Herewith, it is necessary to separate long-term and short-term effects and get oriented on achieving a long-term stable effect.

However, it is necessary to set "links" between the elements that make up this program, implemented certainly in the field of agricultural production and (sub)programs for the development of industrial production, as well as infrastructure, which significantly affect the development of agricultural production.

It necessarily must be shown in the parameters of the target set of the mentioned state program.

So, when elaborating the integral plan-project for achieving the goals if a given state program, it is necessary to denote the integral goal of program Цint as consisted of a certain locked set of subgoals Цint $=\{$ Цсхп, Цпромпр, Цинфр, Црег, Цэкол\}. (Ц - Goal, схп - agriculture production, промпр - industrial production, инфр information, рег - region, экол - ecology).

Herewith, it is necessary to take into account the contribution to the overall significance of each component of the target set, taking into consideration the relative importance of each component, when implementing the program in specific regional, climatic, environmental and other conditions, taking into account the need to ensure the stable development of strategic industries.

Consequently, it means that each component Цсхп, Цпромпр, Цинфр, Црег, Цэкол of the integral target set Цint is the subset in its turn. Therefore:

Цint $=$ Цсхп U Цпромпр U Цинфр U Црег
U Цэкол

\section{RESULTS}

The components mentioned above - the components of each of the subsets within the target function of the strategic industry development program have different significance. This fact should also be taken into account when implementing the integral development strategy of the industry.

According to the following mechanism, the implementing of the state agricultural production development program, related production and infrastructure on the basis of target budget and mixed funding must be carried out through the integral industry development strategy Цint, formed by the subset of stated goals \{ Цсхп $U$ Цпромпр $\cup$ Цинфр $U$ Црег U Цэкол \} .

The methodology, described in a number of works devoted to solving problems of optimal funding of state projects, programs and the search for optimal solutions, is put into the base of our methodology.

In works, dedicated to the financial modeling problematics, the procedure of ranging goals Ц1, Ц2, ..., Цn is offered, by entering $\alpha i \in[0,1], i=1,2, \ldots, n$, the relevance of achieving the goals by each of group is being determined. At the same time the fulfillment of the norming condition is supposed:

$\sum_{-}(\mathrm{i}=1)^{\wedge} \mathrm{n}$ [ $\left[\alpha_{-} \mathrm{i}=1\right)$ 
The determination of $\alpha \mathrm{i}$ at the stage of creating an integrated target set of the state program for the development of agricultural production, related industries and infrastructure based on targeted budget and mixed financing the Цint should be carried out taking into account the interests of the state, organizations and/or enterprises of the industry and related industries, potential private partners. However, as mentioned by a number of authors, such method of ranging program goals Ц1, Ц2, ..., Цn is semi-empirical to a certain extent. Accordingly, "it is natural to supplement it with the classical method of solving problems of this type - the method of expert assessments in the open control mechanism, which eliminates the manipulation of individual "unfair" experts with their assessments in order to obtain the desired assessment for them, which, of course, violates the objectivity of the final result."

The possibility and algorithm of using the method of expert assessments in the open control mechanism of the state funding program for the development of strategic industries can be viewed.

To do this, the non-decreasing for a certain value $\mathrm{R}$ estimates of the group consisting of $\mathrm{N}$ experts is being arranged:

$r 1 \leq r 2 \leq \ldots \leq r n$

Next, a certain number of auxiliary numbers equal to the number of experts involved $(\mathrm{N})$ is introduced:

$q k=100-100(k-1) / N ; k=1,2, \ldots, N$

Accordingly, these numbers should divide a certain conditional segment $[0 \%, 100 \%]$ by the number of equal parts N. Next, for each number $\mathrm{k}$ the value is being determined:

$\min (\mathrm{rk}, \mathrm{qk})$

Finally, from all obtained minimums the biggest one is selected:

$\operatorname{maxmin}(\mathrm{rk}, \mathrm{qk})$

which will be the result decision in the given methodology.

As researchers notice, in the theory of group decision making it is sustained mathematically that the method described above is the open control mechanism, i.e. protected from manipulation of side experts, according to the theoretical calculations.

Herewith, the following conditions must be observed. The efficiency parameters $\alpha 1, \alpha 2, \ldots, \alpha$ must fulfill the normalization condition, which, in turn, from the standpoint of the probability theory, a priori assumes the completeness and lock of the set of the target set Цi of the state program, including all possible subprograms. However, in the observed open control mechanism, the value $\alpha \mathrm{i}$ is determined apart by experts for each goal set Цi, as a rule, connected to i-th subprogram separately, or by a combination of subprograms. Generally, this fact does not guarantee the fulfillment of the norming condition given above. Consequently, the situation can appear, when:

$\sum_{i=1}^{n} \alpha_{i}=\mathrm{C} \neq 1$

The solution of a such situation is the shift from the obtained expert estimates $\alpha \mathrm{i}$ to the renormed estimates:

$\alpha i *=\alpha i / \mathrm{C}$

This solution recovers the condition for normalizing the significance of each separate goal of a program or subprogram, on the one hand, and does not violate the condition of mandatory relevance of each of the goals of the program/subprogram Цi, on the other hand.

The author's model, taking into account the possible impact of each of the subprojects on the final result, is proposed to be added to.

So, it is supposed that the functions of the impact of each goal of the state program on the final result of the functioning of agricultural production are known. Such a function is most likely to be stochastic in nature and can be deduced from the analysis of world and domestic practice. Consequently:

$\Delta Q c x p i=f i(Ц i$,

Next, in turn:

$\sum i \Delta Q \operatorname{cxp} i=\sum i f i(Ц i$,

So, as a norming condition it comes out:

$\alpha i=\sum i f i(Ц i,) / \sum i \Delta Q c x p i$

Implementation of the integral goal of the state program for the development of the strategic industry Цint requires the allotment of a certain amount of БФint financial resources, which are necessary for its full-fledged and riskfree implementation, provided by government agencies through budget financing.

This integral financing amount must be split for implementation of programs and subprograms goals Ц1, Ц $2, \ldots$, Цn with corresponding amounts of resources БФi = БФ (Ці), $\mathrm{i}=1,2, \ldots, \mathrm{n}$.

For the completeness of the model and taking into account existing realities, it can also be assumed that the obtained financing amounts of БФi, in the conditions of the financial crisis, will, as a rule, be insufficient for the full and risk-free achievement of each of the goals of the Цi of the state program for the development of strategic sectors:

$\sum_{i=1}^{n}$ БФ $\left(\bigsqcup_{i}\right) \leq Б \Phi_{i n t}$ 


\section{DISCUSSIONS}

The issue comes to the availability and cost of other sources of financing. It is noted once again that the amount of given budget resources provided for the implementation of the program [БФ】_int supposes full funding of the program and the achievement of each of the goals of the Ці program and subprograms.

However, taking into account local realities as a mechanism for involving regional authorities and municipalities, if the program provides the use of cofinancing mechanisms, which is common for local practice, the need to attract private investment funds will be included in the model. Consequently, it is believed, that the implementation of the state program will require to attract investment funds ЧФj, $\mathrm{j}=1,2, \ldots, \mathrm{m}$, which finance (co-finance) the organizational and economic activities for fulfillment the goals Цi of the program.

To optimize and manage the investing process, the following parameters are entered:

инвіј - the financing amount of a fund ЧФј when implementing the Ці project.

Except it, the following parameters are considered to be known:

pj - fund unit cost of ЧФj, j $=1,2, \ldots, \mathrm{m}$.

Finally, the maximum possible amounts of budget funding БФi for each project Ц1, Ц2, ..., Цn must be considered as known. Thus, the next limits of maximum financing amounts for the state program are obtained:

$\sum_{j=1}^{m} \mathrm{p}_{j} \times$ инв $_{i j} \leq$ БФ $\Phi_{i}, i=1,2, \ldots, n$

Accordingly, when the total amount of available budget financing БФint $=$ БФ(Цint), which is laid down for the implementation of the entire state development program for agricultural production and related industries, is known, the problem of dividing the program into subprograms БФi $=$ БФ(Цi) and financing the achievement of goals Цi of each of the forming streams arises.

The ranking of the significance of Цi goals by their degree of influence on sectoral and intersectoral development and the achievement of stable functioning of enterprises/organizations of the strategic industry can be achieved by introducing the values $\alpha \mathrm{i} \in[0,1], \mathrm{i}=1,2, \ldots$, $\mathrm{n}$, which determine the relative significance of the target set Цi of each of the flows - subprograms. In its turn, it determines the integral target function of the entire state program for development totally:

$\mathrm{F}\left(\bigsqcup_{\text {int }}\right)=\sum_{i=1}^{n} \alpha_{i} \times Б \Phi_{i}$

For the final determination of the parameters of a possible set of solutions to the goal function, it is necessary to set, in addition to the maximum amounts of budget financing, the maximum possibilities of private financing - the limit values of the capacities $\mathrm{Vj}$ of private investment funds (investors) for the use of financing means:

$$
\text { БФ }(Ф j)=\sum_{i=1}^{n} \mathrm{p}_{\mathrm{j}} \times \text { инв }_{\mathrm{ij}} \leq \mathrm{Vj}, \mathrm{j}=1,2, \ldots, \mathrm{m}
$$

Taking into account the noted limits on the parameters for controlling the process of implementing the state program инвіj and the goal function of the process, an economic and mathematical model of the optimal policy for stable development of enterprises/organizations of strategic industries is obtained, which takes into account the parameters and priorities of this development, and looks like:

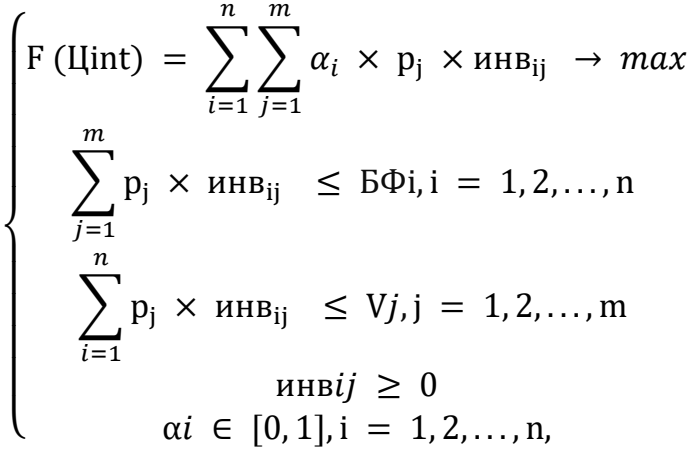

$$
\begin{aligned}
& \sum_{i=1}^{n} \alpha_{i}=1
\end{aligned}
$$

\section{CONCLUSION}

The proposed model is a linear programming problem and, therefore, in accordance with the properties of tasks of this type, it always allows finding the optimal solution Цintopt $=\{Ц 1$ opt, Ц2opt, ..., Цnopt $\}$ using the traditional simplex method, if necessary, using the properties of mutually dual problems.

Also, when the first two systems of limits on funds flow control parameters инвіj look like the equations, it is possible to apply methods for solving the transportation problem with logistic cost coefficients:

$\operatorname{cij}=\alpha \mathrm{i} \times \mathrm{pj}$

Returning to the problem of performance audit, it should be noted that in each group of goals of the general program Цсхп, Цпромпр, Цинфр, Црег, Цэкол, there are the most significant subprograms, which are specific to the effectiveness of the entire integral program as a whole and taking into account the characteristics of the studied enterprise, industry, region. They can be set on the basis of functional analysis for the statistics data, according to the given method. It is obvious, that particularly their implementation must be conducted the first.

Thus, with the use of the given model, it is possible to get a certain set of solutions on own parameters, which are close to the optimal. Consequently, it is possible to use 
Association Conference, IBIMA 2019: Education Excellence and Innovation Management through Vision 2020, 2019, pp. 3235-3240.

[10]V.A. Plotnikov, G. Fedotova, E. Popkova, A. Kastyurina, HARMONIZATION OF STRATEGIC PLANNING INDICATORS OF TERRITORIES' SOCIOECONOMIC GROWTH, Regional and Sectoral Economic Studies. 15(2) (2015) 105-114.

Plotnikov, V. Plotnikov, Competitive regional clusters:
Plantean, A. International experience, E3S Web of Conferences, 2019.

[2] E.A. Borkova, M.A. Barsukova, V.A. Plotnikov, L.V. Vatlina, Comparative analysis of tools for estimation of investment climate of territories, Humanities and Social Sciences Reviews, 2019

[3] S. Ershova, E.Smirnov Conceptual Justification of Town-Planning Design Standards for Streets and Roads in Large Cities for Ensuring Traffic Safety. Transportation Research Procedia, 20, 2017, pp. 180184.

[4] G. Karpova, G. Julmukhamedova, Models for Estimating Human Capital Losses Due to TrafficRelated Deaths. Transportation Research Procedia, 20, 2017, 267-271.

[5] M. Kerimov, R. Safiullin, A. Marusin, Evaluation of Functional Efficiency of Automated Traffic Enforcement Systems. Transportation Research Procedia, 20, 2017, pp. 288-294.

[6] A. Kvitko, B. Karpov, P. Petukhov, A. Ushakov , Criteria for Substantiation of Rational Pavement Design as Bases of Traffic Safety throughout Life Cycle of Transport Structures. Transportation Research Procedia, 20: 384-392.

[7] I. Makarov, N. Morozova, T. Samoylova, V. Plotnikov, Spatial development as a factor of cities' sustainability // E3S Web of Conferences 2019. p. 05034.

[8] I. Makarov, V. Plotnikov, PUBLIC-PRIVATE PARTNERSHIP AS A FINANCIAL INSTRUMENT FOR THE TRANSPORT INFRASTRUCTURE MODERNIZING, MATEC Web of Conferences 2018. p. 05012 .

[9] V. Plotnikov, I. Makarov, O. Levchegov, I. Shamrina, ASSESSING THE IMPACT OF TRANSPORT PROJECTS ON REGIONAL DEVELOPMENT, Proceedings of the 33rd International Business Information Management 